\title{
Tuberculosis prevalence and associated factors among persons with diabetes mellitus after intensified case finding in three West African countries
}

\author{
Ablo Prudence Wachinou, ${ }^{1,2}$ Serge Ade, ${ }^{2,3}$ Maimouna Ndour Mbaye, ${ }^{4}$ Boubacar Bah, ${ }^{5}$ Naby Baldé, ${ }^{6}$ Jules \\ Gninkoun, ${ }^{1}$ Wilfried Bekou, ${ }^{2}$ Marie Sarr, ${ }^{7}$ Oumou Bah Sow, ${ }^{5}$ Dissou Affolabi, ${ }^{1,2}$ Corinne Merle ${ }^{8,9}$ \\ ${ }^{1}$ Faculty of School of Medicine, University of Abomey-Calavi, Cotonou, Benin \\ ${ }^{2}$ National Tuberculosis Programme of Benin, Cotonou, Benin \\ ${ }^{3}$ Faculty of Medicine, University of Parakou, Parakou, Benin \\ ${ }^{4}$ Centre de Diabétologie Marc Sankalé, Dakar, Senegal \\ ${ }^{5}$ Service de Pneumophtisiologie, Centre National Hospitalier Ignace Deen, Conakry, Guinea \\ ${ }^{6}$ Service d'endocrinologie, Centre Hospitalier Universitaire Donka, Conakry, Guinea \\ ${ }^{7}$ National Tuberculosis Programme of Senegal, Dakar, Senegal \\ ${ }^{8}$ Tropical Disease Research Special Programme, World Health Organization, Geneva, Switzerland \\ ${ }^{9}$ London School of Hygiene and Tropical Medicine, LSHTM, London, UK
}

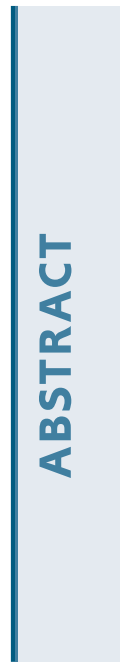

\begin{abstract}
Background: To determine the prevalence of tuberculosis (TB) and associated factors in persons with diabetes mellitus (DM) in Benin, Guinea and Senegal.

Patients and Method: A cross-sectional study was conducted in the largest DM center in each country. Participants systematically underwent clinical screening and chest radiography. Participants who were symptomatic or with abnormal radiography underwent bacteriological investigations (sputum smear, Xpert MTB/RIF and culture) on sputum. Participants with no TB at enrolment were re-examined for TB six months later. Logistic regression was performed to identify factors associated with TB.

Results: There were 5,870 DM patients: 1,881 (32.0\%) in Benin, 1,912 (32.6\%) in Guinea and 2,077 (35.4\%) in Senegal. Out of these, 114 had bacteriologically-confirmed TB, giving a pooled prevalence of $1.9 \%(95 \% \mathrm{CI}=1.6-2.3)$. TB prevalence was $0.5 \%(95 \% \mathrm{CI}=0.3-1.0), 2.4 \%(95 \% \mathrm{CI}=1.8-3.2)$ and $2.8 \%(95 \% \mathrm{CI}=2.2-3.6)$, respectively, in Benin, Guinea and Senegal. Factors associated with an increased odds of TB diagnosis were a usual residence in Guinea $(\mathrm{aOR}=2.62 ; 95 \% \mathrm{CI}=1.19-5.77 ; \mathrm{p}=0.016)$ or in Senegal $(\mathrm{aOR}=3.73 ; 95 \% \mathrm{CI}=1.85-7.51 ; \mathrm{p}<0.001)$, the age group of 3549 years $(\mathrm{aOR}=2.30 ; 95 \% \mathrm{CI}=1.11-4.79 ; \mathrm{p}=0.025)$, underweight $(\mathrm{aOR}=7.34 ; 95 \% \mathrm{CI}=4.65-11.57 ; \mathrm{p}<0.001)$ and close contact with a $\mathrm{TB}$ case $(\mathrm{aOR}=2.27 ; 95 \% \mathrm{CI}=1.37-3.76 ; \mathrm{p}=0.002)$. Obesity was associated with lower odds of TB $(\mathrm{aOR}=0.20 ; 95 \% \mathrm{CI}=0.06-0.65 ; \mathrm{p}=0.008)$.

Conclusion: TB is prevalent among DM patients in Benin, Guinea and Senegal and higher than among the general population. The findings support the need for intensified case finding in DM patients in order to ensure systematic early detection of TB during the routine consultation process.
\end{abstract}

Key words: Tuberculosis; diabetes mellitus; disease burden; risk factors; West Africa.

Correspondence: Wachinou Ablo Prudence, Faculty of School of Medicine, University of Abomey-Calavi, Cotonou, Benin. Tel. +229.67 .173068$ E-mail: wachinouprudence@yahoo.fr

Contributions: APW, participated to the study conception, data acquisition, analyzed and interpreted the data, wrote the first draft of the manuscript; SA, analyzed and interpreted the data and was a major contributor in writing the manuscript; MNM, participated to data acquisition, analyzed and interpreted the data, critically reviewed the manuscript; $\mathrm{BB}, \mathrm{NB}$, participated to data acquisition, analyzed and interpreted the data, critically reviewed the manuscript; JG, participated to data acquisition, interpreted the data, critically reviewed the manuscript; WB, analyzed and interpreted the data, critically reviewed the manuscript; MS, participated to data acquisition, interpreted the data, critically reviewed the manuscript; OBS, participated to data acquisition, analyzed and interpreted the data, critically reviewed the manuscript; DA, participated to the study conception, data acquisition, analyzed and interpreted the data, and was a major contributor in writing the manuscript; CM, designed the study, participated to data acquisition, analyzed and interpreted the data, and was a major contributor in writing the manuscript. All authors approved the final version of the manuscript to be published.

Conflict of interest: The authors declare that they have no competing interests.

Funding: This project was funded through a grant from Expertise France, Ministry of Foreign Affairs of France (Grant N${ }^{\circ}$ 14SANIN210). Funders had no inputs in the study design, data analysis and manuscript writing.

Availability of data and materials: The dataset used during the current study is available from the corresponding author on reasonable request.

Ethics approval and consent to participate: Local ethics approval was obtained from the National Ethics Committee of each country: $\mathrm{N}^{\circ} 101 / \mathrm{MS} / \mathrm{DC} / \mathrm{SGM} / \mathrm{DFR} / \mathrm{CNERS} / \mathrm{SA}$ dated on $14^{\text {th }}$ October 2015 (Benin); $\mathrm{N}^{\circ} 55 / \mathrm{CNERS} / 15$ dated on $25^{\text {th }}$ June 2015 (Guinea); $\mathrm{N}^{\circ} 151 / \mathrm{MSAS} / \mathrm{DPRS} / \mathrm{CNERS}$ ) dated on $19^{\text {th }}$ August 2015 (Senegal). Data were collected anonymously using a unique identifier. All databases were kept confidentially and were protected with a password, only accessible to key persons involved in the study. All participants gave written consent.

Consent for publication: Not applicable. 


\section{Introduction}

Tuberculosis (TB) is one of the deadliest diseases in humankind history [1]. One of the targets of the World Health Organization (WHO) End TB strategy is to reduce the incidence of TB by $90 \%$ in 2035 compared to 2015 . The pillar one of this End TB strategy emphasizes the importance of early detection of TB in all people, especially in those at high risk [2]. Countries and organizations involved in TB control are therefore encouraged to intensify TB detection by systematically screening high-risk populations. Persons with diabetes mellitus (DM) are known to be at higher risk of TB compared with the general population $[3,4]$. Previous studies have demonstrated a bi-directional link between DM and TB. DM increases the risk of TB by three times, it complicates TB diagnosis and management and can negatively affect TB treatment outcomes by increasing the risk of failure and death. On the other side, TB can impair diabetes management by causing stress-related hyperglycemia, thereby prompting more complications [4].

In 2019, 468 million people were estimated by the International Diabetes Foundation to have DM [5]. Projections show a dramatic situation worldwide, and particularly in low- and middle-income countries (LMIC) where $75 \%$ of all people with this disease may be found [5]. The looming epidemic of DM may hamper the efforts made by the global community in these last two decades to end TB [6]. A modelling analysis showed that an increase by $25 \%$ of DM worldwide would reverse the current downward trend of TB incidence, which would be increased by $8 \%$ by 2035 [7]. Unfortunately, the DM epidemic, especially in subSaharan Africa where health service provision for chronic diseases is poor, constitutes a serious threat for TB control [8]. Assessing the burden of TB in DM patients is therefore crucial at country/regional level to inform decisions on how to better control the dual epidemic of DM and TB [9]. Furthermore, there is a scarcity of data on the potential factors associated with TB in DM patients in the African population.

The current study aimed to determine in three West African settings, namely Benin, Guinea and Senegal, the prevalence of bacteriologically confirmed pulmonary TB (BCPTB) among DM patients, as well as the associated risk factors.

\section{Patients and Methods}

\section{Study design and countries involved}

This was a multicountry cross-sectional study conducted between October 2015 and March 2017 in Benin, Guinea and Senegal.

\section{Study sites}

The study was conducted in the largest DM center in each of the countries. In Benin, the study was conducted at "Banque d'Insuline d'Akpakpa" which holds the highest number of DM patients in Cotonou, the economic capital. Patients are usually managed on an outpatient basis. Other critical cases are referred to university hospitals. In Guinea, the study was conducted at the Diabetes department of Donka University Hospital where patients are managed both on an outpatient and inpatient basis. In Senegal, the study was implemented at Centre Marc Sankalé of Dakar, a specialized center for diabetes management from the university hospital Abass Ndao of Dakar where patients are also managed on both an outpatient and inpatient basis.
According to previous data, the prevalence of DM in the population was $5.1 \%$ in Benin, $4.1 \%$ in Guinea and $5.1 \%$ in Senegal, respectively [10]. The incidence of TB in the general population was $55,176,117$ per 100,000 population, respectively, in Benin, Guinea and Senegal [11].

\section{Population}

All DM patients who were receiving care in one of the selected centers and who gave their formal consent were eligible for the study. Those who were already diagnosed with TB and were on treatment prior to the survey were not included; 2,000 diabetic patients per country were planned to be recruited for a total of 6,000 participants for the three centers. Study procedures included sequential recruitment of participants up to 20 per day to avoid excessive workload for the laboratory teams.

\section{Study procedures}

All DM patients, who were included in the study, were systematically screened for presumptive TB symptoms based on the WHO 4-items questionnaire (cough, fever, night sweats and weight loss) [12], followed by a chest-Xray (CXR), except for pregnant women. Those with at least one presumptive TB symptom or with an abnormal chest X-ray were asked to produce two sputum samples (one on the spot and the other one in the early morning) for fluorescence auramine microscopy, Xpert/MTB/RIF and mycobacterial culture on Lowenstein-Jansen solid media [13]. All bacteriological tests were performed at the TB reference laboratory of each country.

In order to detect any undiagnosed TB case, all DM patients who were not diagnosed with active $\mathrm{TB}$ at the enrolment visit were invited for a new TB-related investigation six months later. After clinical assessment, they were again requested to produce sputum samples for microscopy and culture.

Diabetic patients with active TB were referred for treatment to a basic management unit.

\section{Data variables and collection}

The following data were collected: sociodemographic and anthropometric characteristics, type of DM and its duration, clinical characteristics such as cough, fever, weight loss, nocturnal sweating, hemoptysis, smoking habits, BCG scar, and contacts, CXR features and TB-status. Height, measured with a rigid gauge, the participant standing upright, with knees straight, heels joined and pressed against the wall, was the distance from the top of the head to the soles of the feet. He/she was then weighed in a standing position, using an electronic scale, with as little clothing on as possible and without shoes. Data were collected by trained clinical investigators who were involved in the study, using a pre-validated questionnaire.

\section{Training of clinical investigators}

All clinical investigators were previously trained onsite by the study management team on the different phases of the study. This consisted of TB symptom screening, clinical examination, bacteriological investigations (sputum smear, Xpert MTB/RIF, mycobacterial culture) and requesting a CXR. In addition, they were briefed on CXR interpretation by experienced chest physicians. Refreshing training was organized on a quarterly basis by the country study manager.

\section{Quality control}

In each site, a local monitor was in charge of monitoring data collection weekly. Clinical monitoring visits were conducted by an external monitor every 3 months to double check the validity of the 
study results and compare critical data such as patient's eligibility criteria, clinical symptoms, laboratory and CXR results against source documents. Similarly, laboratory results were crosschecked every 3 months by a senior laboratory officer to ensure compliance with all laboratory procedures.

\section{Diagnostic criteria}

BCPTB: A participant was diagnosed with TB based on a positive result of acid-fast bacilli seen on sputum smear microscopy, a positive result of the Xpert MTB/RIF assay or mycobacterial culture, either at the initial assessment or at the sixth month follow up visit (for those who were not diagnosed with $\mathrm{TB}$ at the first visit).

Nutritional status: This was assessed with body mass index (BMI, $\mathrm{kg} / \mathrm{m}^{2}$ ) that was calculated using the following formula (Weight (in $\mathrm{kg}$ )/Size (in $\mathrm{m}^{2}$ ). Four categories were identified: underweight $\left(\mathrm{BMI}<18.5 \mathrm{~kg} / \mathrm{m}^{2}\right)$, normal status $(\mathrm{BMI}=18.5-24.99$ $\left.\mathrm{kg} / \mathrm{m}^{2}\right)$, overweight $\left(\mathrm{BMI}=25-29.99 \mathrm{~kg} / \mathrm{m}^{2}\right)$ and obesity $(\mathrm{BMI} \geq 30$ $\left.\mathrm{kg} / \mathrm{m}^{2}\right)$.

Close contact with a TB case: A person who shared the same enclosed living space for one or more nights or for frequent or extended periods during the day with an active TB case [14].

Smoking habits: Participants were categorized into three groups: non-smokers, ex-smokers and current smokers.

$B C G$ vaccination status: This was assessed by examination of the BCG scar mainly on the left forearm. The scar was either present, absent or doubtful.

$T B$ suggestive CXR features: These included nodular lesions, infiltrates, cavitation located in the upper pulmonary zones or elsewhere in the lungs, with or without pleural effusion, lymphadenopathy [15].

\section{Study coordination}

The study was coordinated by an officer based in one country, who was assisted by a country study manager in the remaining two other countries.

\section{Data management and analysis}

Data were double entered in an access database by two local clerks and clean data were then analyzed using R-3.4.3 software. Categorical variables were expressed as percentages. The number of DM patients needed to screen to get one TB case was calculated by dividing the number of patients screened by the number of TB cases. Comparisons between two categorical variables were made using the chi-square test (or Fisher's exact test if applicable). Potential factors associated with TB were selected from a large literature review. These included: age, sex, type of DM and duration, DM treatment, close contact with a TB case, BMI, BCG vaccination and smoking habits. A bivariate analysis was performed. This was followed by a multiple logistic regression with all variables showing a $p$ less than 0.25 on bivariate analysis. A backward stepwise strategy was performed. The Hosmer-Lemeshow test was used to validate the model.

\section{Results}

\section{Baseline characteristics of participants}

Overall, out of 5,908 DM patients enrolled in the study, 5,870 were finally recruited: 1,881 (32.0\%) from Benin, 1,912 (32.6\%) from Guinea and 2,077 (35.4\%) from Senegal (Figure 1). Baseline characteristics of participants are shown in Table 1. From all sites, most patients were in the age range of 35-64 years $(69.9 \%)$ and were female $(69.8 \%)$. Being underweight was found in $4.3 \%$ of participants in Benin, in $9.7 \%$ in Guinea and in $9.0 \%$ in Senegal. Over nine out of ten patients had type 2 DM in each of the countries. DM was diagnosed within the last five years in more than half of the participants $(58.3 \%$ in Benin, $67.9 \%$ in Guinea and $60.2 \%$ in Senegal).

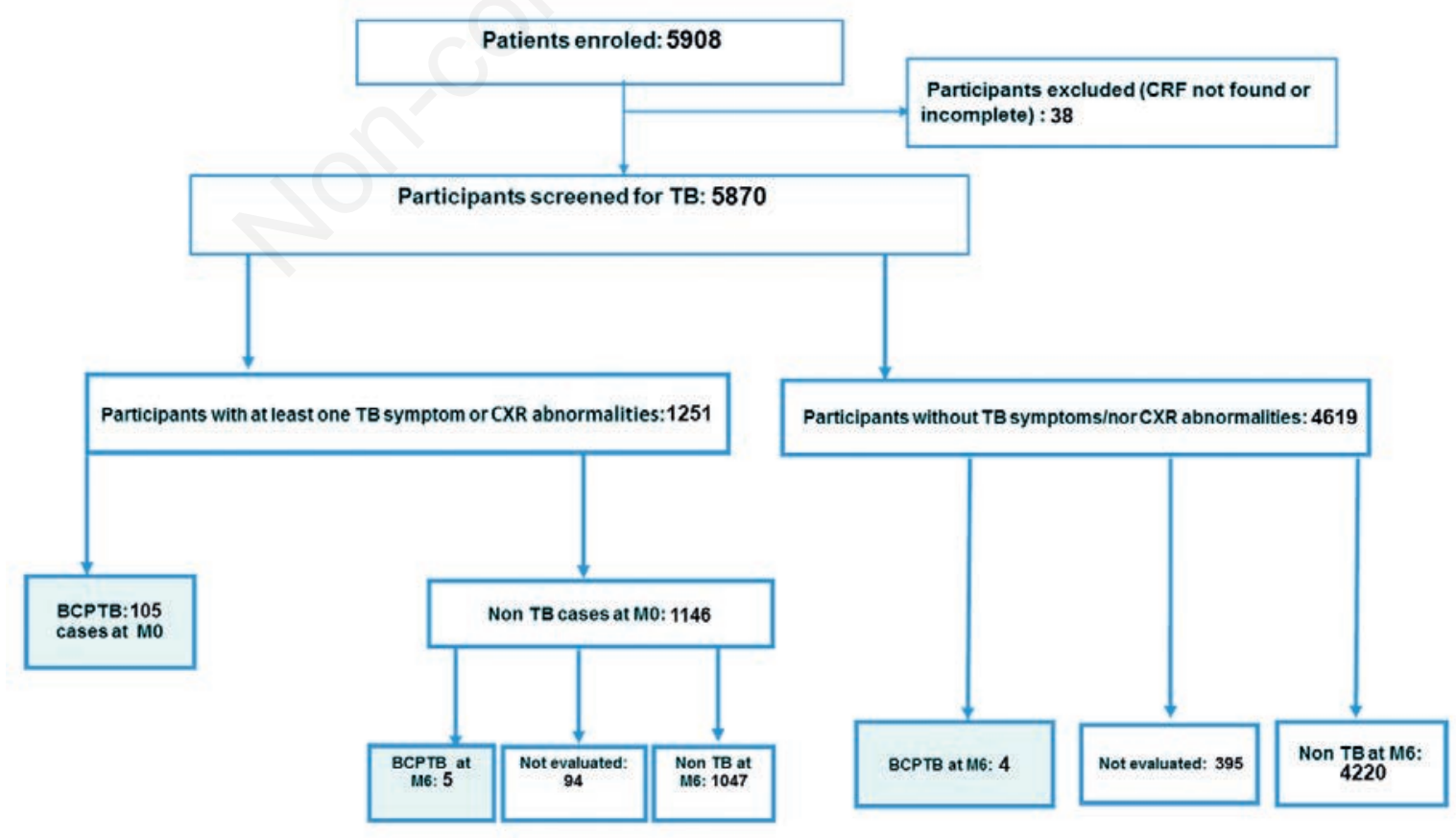

Figure 1. Tuberculosis screening among patients with diabetes mellitus in 3 diabetes centers in Benin, Guinea and Senegal. BCPTB, Bacteriologically confirmed tuberculosis; TB, tuberculosis; CXR, Chest X-Ray; M, month; CRF, Case Report form. 


\section{Clinical features and prevalence of BCPTB}

Out of the 5,870 participants, 1,183 (20.2\%) complained of at least one presumptive TB symptom. There were also $68(1.2 \%)$ participants who, although being clinically asymptomatic, had an abnormal CXR (Figure 1). Among participants who were symptomatic, there were fewer who had symptoms in Benin (10.4\%) compared with Guinea $(22.2 \% ; \mathrm{p}<0.001)$ and Senegal $(27.1 \%$; $\mathrm{p}<0.001)$. In terms of frequency of symptoms, the most commonly reported was cough $(12.5 \%)$, followed by night sweats $(7.4 \%)$ and fever $(7.3 \%)$ (Table 2). Overall, 114 DM patients were diagnosed with BCPTB in the three centers: 105 at the initial assessment and 9 at the 6-month assessment. The overall pooled prevalence was $1.9 \%$ (95\% CI:1.6-2.3). Benin showed the lowest prevalence with 0.5\% (95\%CI:0.3-1.0) while Guinea and Senegal showed a higher but similar prevalence with respectively $2.4 \%$ (95\%CI:1.8-3.2) and $2.8(95 \% \mathrm{CI}: 2.2-3.6)$. The number needed to screen to diagnose one TB case was estimated at approximately 200 DM patients in Benin, 47 in Guinea and 36 in Senegal.

\section{Factors associated with BCPTB in diabetic patients}

Potential factors associated with TB in diabetic patients in the three countries are shown in Table 3. After multivariate analysis, living in Guinea $(\mathrm{aOR}=2.62 ; 95 \% \mathrm{CI}=1.19-5.77 ; \mathrm{p}=0.016)$ or in Senegal $(\mathrm{aOR}=3.73 ; 95 \% \mathrm{CI}=1.85-7.51 ; \mathrm{p}<0.001)$ was associated with a significantly higher risk of being diagnosed with BCPTB than residing in Benin, after adjustment with confounders. Likewise, belonging in the age group of $35-49$ years $(\mathrm{aOR}=2.30$; $95 \% \mathrm{CI}=1.11-4.79 ; \mathrm{p}=0.025)$, being underweighted $(\mathrm{aOR}=7.34$; $95 \% \mathrm{CI}=4.65-11.57 ; \mathrm{p}<0.001)$ or having a close contact with a TB case $(\mathrm{aOR}=2.27 ; 95 \% \mathrm{CI}=1.37-3.76 ; \mathrm{p}=0.002)$ increased the risk of being diagnosed with TB. In addition, obesity was found to be associated with a lower risk of $\mathrm{TB}(\mathrm{aOR}=0.20 ; 95 \% \mathrm{CI}=0.06-0.65$; $\mathrm{p}=0.008)$.

\section{Discussion}

This is the first study that has attempted to determine the over-

Table 1. Demographics and characteristics of persons with diabetes mellitus in three diabetes centers in Benin, Guinea and Senegal $(n=5870)$.

\begin{tabular}{|c|c|c|c|c|}
\hline & $\begin{array}{l}\text { Benin } \\
\text { n (\%) }\end{array}$ & $\begin{array}{l}\text { Guinea } \\
\text { n (\%) }\end{array}$ & $\begin{array}{c}\text { Senegal } \\
\text { n }(\%)\end{array}$ & All n (\%) \\
\hline $\begin{array}{l}\text { Age (years) } \\
<35 \\
35-49 \\
50-64 \\
\geq 65\end{array}$ & $\begin{array}{l}153(8.1) \\
526(28.0) \\
840(44.7) \\
362(19.2)\end{array}$ & $\begin{array}{l}234(12.2) \\
477(25.0) \\
791(41.4) \\
410(21.4)\end{array}$ & $\begin{array}{r}141(6.8) \\
502(24.2) \\
967(46.5) \\
467(22.5)\end{array}$ & $\begin{array}{c}528(9.0) \\
1,505(25.6) \\
2,598(44.3) \\
1,239(21.1)\end{array}$ \\
\hline $\begin{array}{l}\text { Gender } \\
\text { Male } \\
\text { Female }\end{array}$ & $\begin{array}{c}646(34.3) \\
1,235(65.7)\end{array}$ & $\begin{array}{c}617(32.3) \\
1,295(67.7)\end{array}$ & $\begin{array}{c}510(24.6) \\
1,567(75.4)\end{array}$ & $\begin{array}{l}1773(30.2) \\
4097(69.8)\end{array}$ \\
\hline $\begin{array}{l}\text { Body mass index }\left(\mathrm{kg} / \mathrm{m}^{2}\right) \\
\quad<18.5 \\
18.5-24.99 \\
25.0-29.99 \\
\geq 30\end{array}$ & $\begin{array}{c}81(4.3) \\
580(30.8) \\
605(32.2) \\
615(32.7)\end{array}$ & $\begin{array}{r}186(9.7) \\
835(43.7) \\
566(29.6) \\
325(17.0)\end{array}$ & $\begin{array}{l}186(9.0) \\
987(47.5) \\
578(27.8) \\
326(15.7)\end{array}$ & $\begin{array}{c}453(7.7) \\
2,402(40.9) \\
1,749(29.8) \\
1,266(21.6)\end{array}$ \\
\hline $\begin{array}{l}\text { Smoking habits } \\
\text { Never smoker } \\
\text { Current/ex-smoker }\end{array}$ & $\begin{array}{c}1,837(97.7) \\
44(2.3)\end{array}$ & $\begin{array}{c}1593(83.3) \\
319(16.7)\end{array}$ & $\begin{array}{c}1,878(90.4) \\
199(9.6)\end{array}$ & $\begin{array}{c}5,308(90.4) \\
562(9.6)\end{array}$ \\
\hline $\begin{array}{l}\text { Type of diabetes } \\
\text { Type } 1 \\
\text { Type } 2 \\
\text { Other }\end{array}$ & $\begin{array}{c}57(3.0) \\
1,801(95.8) \\
23(1.2)\end{array}$ & $\begin{array}{c}210(11.0) \\
1,702(89.0) \\
0(0)\end{array}$ & $\begin{array}{c}196(9.5) \\
1,872(90.1) \\
9(0.4)\end{array}$ & $\begin{array}{c}463(7.9) \\
5,375(91.6) \\
32(0.5)\end{array}$ \\
\hline $\begin{array}{l}\text { Duration of diabetes (years) } \\
<1 \\
1-5 \\
6-10 \\
>10\end{array}$ & $\begin{array}{l}462(24.6) \\
634(33.7) \\
391(20.8) \\
394(21.0)\end{array}$ & $\begin{array}{l}532(27.8) \\
767(40.1) \\
332(17.4) \\
281(14.7)\end{array}$ & $\begin{array}{l}382(18.4) \\
760(36.6) \\
368(17.7) \\
567(27.3)\end{array}$ & $\begin{array}{l}1,376(23.4) \\
2,161(36.8) \\
1,091(18.6) \\
1,242(21.2)\end{array}$ \\
\hline $\begin{array}{l}\text { Diabetic treatment } \\
\text { Hygiene-dietetic measures only } \\
\text { Insulin } \\
\text { Oral anti diabetic drugs }\end{array}$ & $\begin{array}{c}87(4.6) \\
300(15.9) \\
1,494(79.5)\end{array}$ & $\begin{array}{c}34(1.8) \\
710(37.1) \\
1,168(61.1)\end{array}$ & $\begin{array}{c}278(13.4) \\
515(24.8) \\
1,284(61.8)\end{array}$ & $\begin{array}{c}399(6.8) \\
1,525(26.0) \\
3,946(67.2)\end{array}$ \\
\hline $\begin{array}{l}\text { Close contact with a TB case } \\
\text { Yes } \\
\text { No }\end{array}$ & $\begin{array}{c}127(6.8) \\
1,754(93.2)\end{array}$ & $\begin{array}{c}282(14.8) \\
1,630(85.2)\end{array}$ & $\begin{array}{c}148(7.1) \\
1,929(92.9)\end{array}$ & $\begin{array}{c}557(9.5) \\
5,313(90.5)\end{array}$ \\
\hline $\begin{array}{l}\text { BCG vaccination status } \\
\text { Present } \\
\text { Doubtful/absent }\end{array}$ & $\begin{array}{c}1,415(75.2) \\
466(24.8)\end{array}$ & $\begin{array}{c}1,753(91.7) \\
159(8.3)\end{array}$ & $\begin{array}{c}1,730(83.3) \\
347(16.7)\end{array}$ & $\begin{array}{c}4,898(83.4) \\
972(16.6)\end{array}$ \\
\hline Total & 1,881 & 1,912 & 2,077 & 5,870 \\
\hline
\end{tabular}


all prevalence of TB among DM patients in three West African countries. There were some interesting findings that deserve consideration.

First, the overall pooled prevalence of BCPTB among diabetic patients in the three settings included in the study was $1.9 \%$. Potentially, this represents 1,900 BCPTB cases who could have been diagnosed if 100,000 diabetic patients were screened. This prevalence of BCPTB is much higher than the one observed in the general population which ranges from 55 per 100,000 in Benin to 176 per 100,000 in Guinea [11]. This provides further evidence that DM patients constitute a huge and important reservoir to consider for intensified TB case finding, in all settings, especially in resource-constrained settings. The true prevalence of TB would even have been higher if the other types of TB cases such as those who have been clinically diagnosed or who had developed extrapulmonary TB had been included. Compared with previously published literature, our overall and country-specific prevalence of TB fell within the range of $0.38 \%$ to $14 \%$ according to a systematic review published in 2017 [9]. However, the prevalence remains much lower than the prevalence $(5.13 \%)$ found in a meta-analysis that involved several other sub-Saharan African countries, although none of these were from West Africa [16].

Second, surprisingly the prevalence of BCPTB cases reported from Benin $(0.5 \%)$, was five to six times lower than that observed in Guinea and in Senegal, respectively at $2.4 \%$ and $2.8 \%$. One possible explanation may relate to differences in the profiles of DM patients who were included in the different study sites. For instance, while participants from Benin were recruited in a center providing care on an outpatient basis, those from Guinea and Senegal were from centers routinely managing both inpatients and outpatients. The higher frequency of TB among those who were admitted in hospital with acute conditions and perhaps DM out of control likely contributed to increase the prevalence of the disease in Guinea and Senegal. The lower proportion of DM patients with presumptive TB symptoms in Benin (10.4\%) compared with Guinea (22.2\%) and Senegal (27.1\%) corroborates this hypothesis. One major lesson learnt from this for future investigations is to consider both in and out DM patients to keep close to the true prevalence of TB in this specific population. Another possible explanation may rely on the overall three times lower prevalence of TB in the general population in Benin compared with the two other countries, with consequently a lower transmission of the disease among patients with DM.

Third, underweight, that was recorded with the highest odds ratio, was an important factor associated with $\mathrm{TB}$; and this has been reported elsewhere [9]. There is a strong interrelation between being underweight and TB. Indeed, TB usually causes weight loss that may lead to underweight, and this happens regardless of the presence of other potential comorbidities. On the other hand, poorly controlled DM and the consequent metabolic decompensation may induce weight loss, that eventually may further impair the immune system and allow the tuberculous bacilli to reactivate $[17,18]$. Underweight or the complaint of weight loss should be used as a key clinical factor to detect DM patients at most risk of being diagnosed with TB. Given the key importance of resources in any screening strategy, the attention to weight loss or being underweight can be very useful in a targeted screening program [19].

Being underweight, through weight loss, may reflect a delay in the diagnosis of TB among these DM patients, who, due to their underlying condition, are mostly followed-up on a regular basis. This contrasts with the general population that only present to health centers in case of disease. This is of concern and stresses the importance of continuous screening for TB in this high-risk group. Such routine screening would prevent from any delay in the diagnosis of TB, since there are usually reported in the literature similarities in the clinical features of both diseases and worse, alteration of TB symptoms due to DM [16]. More work is needed to inform DM patients about presumptive symptoms and signs of TB as well as ensure that they are systematically clinically screened at each routine consultation; and according to our findings, special attention should be given to those aged between 35 and 49 yearsold.

Interestingly, obesity was associated with a lower risk of TB incidence similar to other findings in the literature [20,21]. In one study from Taiwan, DM patients who were obese tended to have a

Table 2. Tuberculosis symptoms presented by persons with diabetes mellitus who were screened for TB in three diabetes centers in Benin, Guinea and Senegal $(n=5870)$.

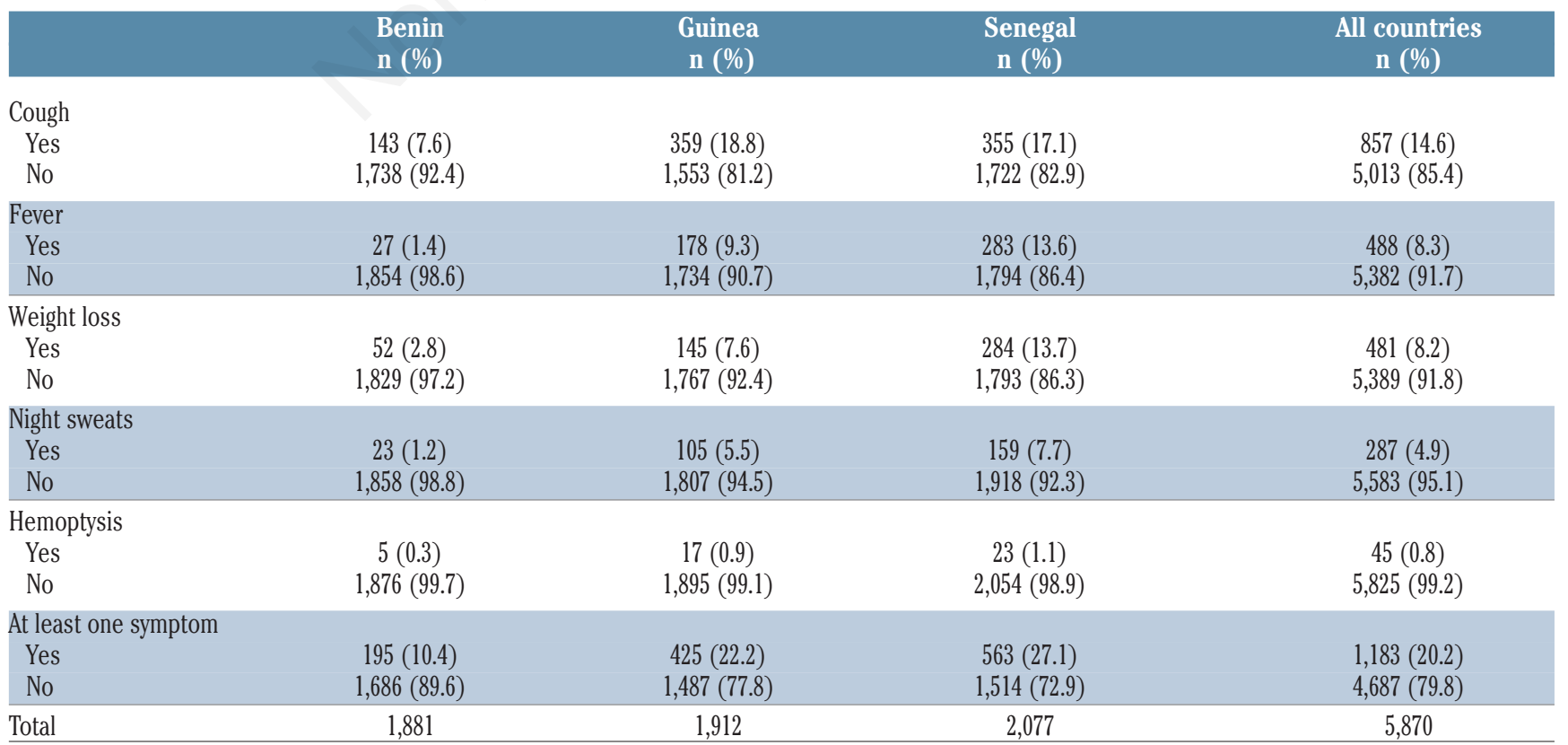


lower risk of developing TB than non-diabetic normal-weight individuals [22]. This lower risk of TB disease of obese DM patients is surprising, since obesity promotes DM, which, in turn, may increase the risk of developing TB, one major symptom of this, being weight loss. Some reports in the literature pointed out the possible influence of the leptin and hypercholesterolemia [22]. Convincing explanations regarding the complex relationship between obesity, DM and TB require further investigations.

Another factor that was found associated with TB was being a close contact with a TB case. We would recommend systematic and complete screening of DM patients when TB is diagnosed among their close contacts. The screening should involve clinical assessment and also CXR and bacteriological investigations.

Elsewhere, other factors associated with TB have mostly been reported from developed settings and these include tobacco and illicit drugs use, lifestyle and harmful alcohol consumption [8,9,13-15]. In the current study, smoking was associated with TB in bivariate analysis, but this was not confirmed after adjusting for potential confounders. Differences in behavioral habits between high- and low-resource settings, despite increasing westernization in poor settings [23], likely contributed to this result. Unfortunately, other risk factors were not included as part of our analysis, due to lack of data on these variables. Future research will address these issues.

The strengths of this study include the large number of DM patients who were recruited in the largest DM center located in the main urban city in each country, and the use of a robust case definition based on bacteriological confirmation. There were also some limitations. First, due to limited resources, we were not able to cover the whole country, including rural settings where the situation may differ, challenging thereby a generalization of findings. However, we believe that the inclusion of the largest DM center in each country gives for the first time in these settings an approximate good picture of the burden of TB in this specific vulnerable group. Second, the sampling process, consisting of recruiting a fixed number of patients daily, may be subject of bias. This

Table 3. Factors associated with tuberculosis in persons with diabetes mellitus in three West African countries.

\begin{tabular}{|c|c|c|c|c|c|c|}
\hline & \multicolumn{2}{|c|}{$\mathbf{T B}$} & \multirow[t]{2}{*}{ c0R (IC95\%) } & \multirow[t]{2}{*}{$\mathbf{p}$} & \multirow[t]{2}{*}{ a0R (IC95\%) } & \multirow[t]{2}{*}{$\mathbf{p}$} \\
\hline & Yes & No & & & & \\
\hline \multicolumn{7}{|l|}{ Countries } \\
\hline Benin & 10 & 1,871 & - & $<0.001$ & - & - \\
\hline Guinea & 46 & 1,866 & $4.61(2.32-9.16)$ & & $2.62(1.19-5.77)$ & 0.016 \\
\hline Senegal & 58 & 2,019 & $5.37(2.74-10.55)$ & & $3.73(1.85-7.51)$ & $<0.001$ \\
\hline \multicolumn{7}{|l|}{ Age (years) } \\
\hline$<35$ & 11 & 517 & - & 0.022 & - & - \\
\hline $35-49$ & 43 & 1,462 & $1.38(0.71-2.70)$ & & $2.30(1.11-4.79)$ & 0.025 \\
\hline 50-64 & 40 & 2,558 & $0.73(0.37-1.44)$ & & $1.22(0.57-2.58)$ & 0.609 \\
\hline$\geq 65$ & 20 & 1,219 & $0.77(0.37-1.62)$ & & $1.18(0.52-2.68)$ & 0.684 \\
\hline \multicolumn{7}{|l|}{ Gender } \\
\hline Male & 53 & 1,720 & - & $<0.001$ & - & - \\
\hline Female & 61 & 4,036 & $0.49(0.34-0.71)$ & & $0.78(0.50-1.22)$ & 0.275 \\
\hline \multicolumn{7}{|l|}{ BMI $\left(\mathrm{kg} / \mathrm{m}^{2}\right)$} \\
\hline$<18.5$ & & 453 & $8.07(5.24-12-41)$ & $<0.001$ & $7.34(4.65-11.57)$ & $<0.001$ \\
\hline $18.5-24.99$ & & 2,402 & - & & 1 & \\
\hline $25.0-29.99$ & & 1,749 & $0.75(0.44-1.29)$ & & $0.85(0.49-1.46)$ & 0.558 \\
\hline$\geq 30$ & & 1,266 & $0.14(0.05-0.48)$ & & $0.20(0.06-0.65)$ & 0.008 \\
\hline \multicolumn{7}{|l|}{ Smoking habits } \\
\hline Never smoker & 88 & 5,220 & - & $<0.001$ & - & - \\
\hline Current/Ex-smoker & 26 & 536 & $2.88(1.84-4.49)$ & & $1.43(0.84-2.44)$ & 0.188 \\
\hline \multicolumn{7}{|l|}{ Type of diabetes } \\
\hline Type 1 & 7 & 456 & - & 0.487 & - & - \\
\hline Type 2 & 106 & 5,269 & $1.31(0.61-2.83)$ & & - & - \\
\hline Other & 1 & 31 & $2.10(0.25-17.62)$ & & - & - \\
\hline \multicolumn{7}{|l|}{ Duration of diabetes (years) } \\
\hline$<1$ & 30 & 1,346 & - & 0.699 & - & - \\
\hline $1-5$ & 37 & 2,124 & $0.78(0.48-1.27)$ & & - & - \\
\hline $6-10$ & 20 & 1,071 & $0.84(0.47-1.48)$ & & - & - \\
\hline$>10$ & 27 & 1,215 & $0.99(0.59-1.68)$ & & - & - \\
\hline \multicolumn{7}{|l|}{ Diabetic treatment } \\
\hline Dietetic measures only & 12 & 387 & - & 0.011 & - & - \\
\hline Insulin & 40 & 1,485 & $0.87(0.45-1.67)$ & & $0.77(0.38-1.58)$ & 0.483 \\
\hline Oral anti diabetics & 62 & 3,884 & $0.51(0.27-0.96)$ & & $0.84(0.43-1.65)$ & 0.626 \\
\hline \multicolumn{7}{|l|}{ Contact with TB case } \\
\hline Yes & 22 & 535 & $2.33(1.45-3.74)$ & $<0.001$ & $2.27(1.37-3.76)$ & 0.002 \\
\hline No & 92 & 5,221 & - & & - & - \\
\hline \multicolumn{7}{|l|}{ BCG vaccination scar } \\
\hline Present & 92 & 4,806 & - & 0.427 & - & - \\
\hline Doubtful/Absent & 22 & 950 & $1.21(0.75-1.94)$ & & - & - \\
\hline
\end{tabular}


arrangement, however, allowed the laboratories involved in the study to continue coping with their daily workloads and other tasks. Third, as stated above, the non-inclusion of those suffering from clinically diagnosed or extrapulmonary TB likely reduced the prevalence of the disease. However, the diagnosis of these two types of TB is difficult and may often be wrong in resource-limited settings, so we feel that it was correct to just focus on BCPTB in this first instance.

\section{Conclusion}

The prevalence of BCPTB among DM patients was higher than in the general population in Benin, Senegal and Guinea. This reinforces the assumption that DM patients may be a large reservoir for TB intensified case finding strategies in the sub-region of West Africa. Some variation between countries was found, with Benin showing a lower prevalence compared to Guinea and Senegal. The risk of diagnosing TB among diabetic patients was significant in adults who were aged 35-49 years-old, who were underweight or who lived with a TB case. These findings may help national TB programmes to implement relevant interventions for TB case detection among DM patients.

\section{Acknowledgements}

Authors acknowledged the contribution of Severin Gossa, Lionel Medenou, Ibrahima Mbaye, for data acquisition, Terence Totah for data analysis and also all the staffs involved in the study at the three study sites in Cotonou, Conakry and Dakar.

\section{References}

1. World Health Organization. Global tuberculosis report 2020. Geneva: World Health Organization; 2020.

2. Uplekar M, Weil D, Lonnroth K, Jaramillo E, Lienhardt C, Dias HM, et al. WHO's new end TB strategy. Lancet 2015;385:1799-801.

3. Martinez N, Kornfeld H. Tuberculosis and diabetes: From bench to bedside and back. Int J Tuberc Lung Dis 2019;23:669-77.

4. Martinez N, Kornfeld H. Diabetes and immunity to tuberculosis. Eur J Immunol 2014;44:617-26.

5. International Diabetes Foundation. IDF diabetes atlas, 4th ed. International Diabetes Foundation, Brussels.

6. Lin Y, Harries AD, Kumar AMV, Critchley JA, van Crevel R, Owiti P, et al. Tackling diabetes mellitus and tuberculosis: a new Union guide on the management of diabetes-tuberculosis. Int J Tuberc Lung Dis 2019;23:771-2.

7. Odone A, Houben RMGJ, White RG, Lönnroth K. The effect of diabetes and undernutrition trends on reaching 2035 global tuberculosis targets. Lancet Diabetes Endocrinol 2014;2:75464.

8. Amberbir A. The challenge of worldwide tuberculosis control: and then came diabetes. Lancet Glob Health 2019;7:e390-1.

9. Workneh MH, Bjune GA, Yimer SA. Prevalence and associated factors of tuberculosis and diabetes mellitus comorbidity: A systematic review. PLoS One 2017;12:1-25.

10. World Health Organization. Diabetes country profile. 2016. Available from: https://www.who.int/diabetes/country-profiles

11. World Health Organization. Tuberculosis country profiles. 2019. Available from: https://worldhealthorg.shinyapps.io $/$ tb profiles $/$ ? inputs_\&entity type $=\% 22 \mathrm{co}$

12. World Health Organization. Systematic screening for active tuberculosis. 2015. Available from: http://apps.who.int/iris/bitstream/handle/10665/181164/9789241549172_eng.pdf

13. World Health Organization. TB diagnostics and laboratory services, information note. Available from: https://www.who. int/tb/dots/lab.pdf

14. World Health Organization. Recommendations for investigating contacts of persons with infectious tuberculosis in low- and middle-income countries. Available from: https://apps.who.int/ iris/handle/10665/77741

15. Nachiappan AC, Rahbar K, Shi X, Guy ES, Mortani Barbosa EJ, Shroff GS, et al. Pulmonary tuberculosis: Role of radiology in diagnosis and management. Radiographics 2017;37:52-72.

16. Wagnew F, Eshetie S, Alebel A, Dessie G, Tesema C, Abajobir AA. Meta-analysis of the prevalence of tuberculosis in diabetic patients and its association with cigarette smoking in African and Asian countries. BMC Res Notes 2018;11:1-7.

17. Restrepo BI, Fisher-Hoch SP, Pino PA, Salinas A, Rahbar MH, Mora F, et al. Tuberculosis in poorly controlled type 2 diabetes: Altered cytokine expression in peripheral white blood cells. Clin Infect Dis 2008;47:634-41.

18. Skowroński M, Zozulińska-Ziólkiewicz D, BarinowWojewódzki A. Tuberculosis and diabetes mellitus - An underappreciated association. Arch Med Sci 2014;10:1019-27.

19. Harries AD, Kumar AMV, Satyanarayana S, Lin Y, Zachariah R, Lönnroth $\mathrm{K}$, et al. Diabetes mellitus and tuberculosis: Programmatic management issues. Int $\mathrm{J}$ Tuberc Lung Dis 2015;19:879-86.

20. Badawi A, Gregg B, Vasileva D. Systematic analysis for the relationship between obesity and tuberculosis. Public Health 2020;186:246-56.

21. Lönnroth K, Williams BG, Cegielski P, Dye C. A consistent log-linear relationship between tuberculosis incidence and body mass index. Int J Epidemiol 2010;39:149-55.

22. Lin HH, Wu CY, Wang CH, Fu H, Lönnroth K, Chang YC, et al. Association of obesity, diabetes, and risk of tuberculosis: Two population-based cohorts. Clin Infect Dis 2018;66:699705.

23. Lee K, Eckhardt J, Holden C. Tobacco industry globalization and global health governance: Towards an interdisciplinary research agenda. Palgrave Commun 2016;2:16037.

Received for publication: 13 May 2021. Accepted for publication: 15 June 2021.

This work is licensed under a Creative Commons Attribution-NonCommercial 4.0 International License (CC BY-NC 4.0).

(C) Copyright: the Author(s), 2021

Licensee PAGEPress, Italy

Multidisciplinary Respiratory Medicine 2021; 16:783

doi:10.4081/mrm.2021.783 